\title{
Variations in population health status: results from a United Kingdom national questionnaire survey
}

\author{
Paul Kind, Paul Dolan, Claire Gudex, Alan Williams
}

Centre for Health

Economics,

University of York,

York YO1 5DD

Paul Kind,

senior research fellow

Paul Dolan,

research fellow

Claire Gudex,

research fellow

Alan Williams,

professor of economics

Correspondence to:

Dr Kind

pk1@york.ac.uk

BMJ 1998;316:736-41

\begin{abstract}
Objective: To measure the health of a representative sample of the population of the United Kingdom by using the EuroQoL EQ-5D questionnaire.

Design: Stratified random sample representative of the general population aged 18 and over and living in the community.

Setting: United Kingdom.

Subjects: 3395 people resident in the United

Kingdom.
\end{abstract}

Main outcome measures: Average values for mobility, self care, usual activities, pain or discomfort, and anxiety or depression.

Results: One in three respondents reported problems with pain or discomfort. There were differences in the perception of health according to the respondent's age, social class, education, housing tenure, economic position, and smoking behaviour.

Conclusions: The EQ-5D questionnaire is a practical way of measuring the health of a population and of detecting differences in subgroups of the population.

\section{Introduction}

The measurement of health is central to the evaluation of health care. By observing the extent of changes in health the benefits and disbenefits of health care for both patients and groups of patients can be evaluated; over the past 25 years several generic measures of health have been developed for use in this way. ${ }^{1-8}$ These instruments were designed for use as general purpose measures of health, independent of diagnostic categorisation or disease severity. Information based on such measures is useful for establishing the degrees of morbidity in the community, enabling different population subgroups to be compared, which would help in assessing health needs or in informing those responsible for allocating health resources. Periodic reassessment of health could provide important data on the extent of any changes in the health of a populationfor example, the extent to which the population is achieving national targets for health. If such standardised information was also routinely collected on individual patients it would provide a simple means of evaluating the outcomes of their health care.

We report on a study in which the EuroQoL EQ-5D questionnaire ${ }^{9}$ was fielded in a survey of the population of the United Kingdom, conducted as part of a wider study of practical ways of measuring health related quality of life. ${ }^{10}$

\section{Subjects and methods}

EQ-5D questionnaire

The EQ-5D questionnaire is a generic measure of health status developed by the EuroQoL Group, an international research network established in 1987 by researchers from Finland, the Netherlands, Sweden, and the United Kingdom. The EQ-5D questionnaire defines health in terms of five dimensions: mobility, self care, usual activities (work, study, housework, family, or leisure), pain or discomfort, and anxiety or depression. Each dimension is subdivided into three categories, which indicate whether the respondent has no problem, a moderate problem, or an extreme problem (appendix). Combinations of these categories define a total of 243 health states. The EQ-5D questionnaire comprises two pages; on the first page respondents record the extent of their problem in each of the five dimensions and on the second page they record their perception of their overall health on a visual analogue scale ( 0 denoting the worst imaginable health state and 100 denoting the best imaginable health state). The validity and reliability of the EQ-5D questionnaire have been tested, ${ }^{11-13}$ as has its application in a range of patient groups. ${ }^{14-16}$ Since the original survey reported here, the EQ-5D questionnaire has been fielded in three national surveys, including the English national health survey-an interview-based survey of about 16000 people. The EQ-5D questionnaire has also been used in population surveys in Spain, Germany, and Canada.

\section{Survey design and methods}

Members of the public aged 18 and over were interviewed as part of a national survey. No upper age limit was stipulated. The sample was based on addresses in England, Scotland, and Wales, selected by postcode. $^{17}$ Eighty postcode areas were chosen, proportionately to the number of addresses in each area, after these areas had been stratified by regional health authority, socioeconomic group, and population density. Seventy six addresses were selected from each postcode area, yielding a total of 6080 addresses. At each of these addresses one adult aged 18 or over was selected using a Kish grid. ${ }^{18}$ Individuals in institutions, hostels, care homes, or bed and breakfast accommodation were excluded from the sample. Of the selected addresses, 12\% were unproductive as they were non-residential, empty, or untraceable. The final sample comprising 3395 subjects was representative of the general population with respect to age, sex, and social class. During the interview, respondents completed the EQ-5D questionnaire and provided information on age, sex, marital state, education, employment, housing tenure, and smoking behaviour. The interviews took place during the last quarter of 1993.

Analysis mainly compared the differences between the population subgroups. It was hypothesised that more health problems would be reported with increasing age, with lower social class, for those registered sick or disabled, and for smokers. $\chi^{2}$ Tests were used for the analysis of the descriptive profile data, and Student's $t$ test was used to test for subgroup differences in the visual analogue scale data. 


\section{Results}

A moderate problem on at least one dimension was reported by $42 \%$ of respondents, whereas only $6 \%$ of respondents reported any extreme problem (table 1). Problems were most often recorded in the pain or discomfort dimension. In subsequent analyses, moderate and extreme categories of each dimension were combined.

The mean state of health recorded on the visual analogue scale was 82.5 (SD 17).

\section{Health and age}

The rates of reported problems increased significantly with age $(\mathrm{P}<0.001)$ for all dimensions (table 2); an exception to this general pattern was the anxiety/ depression dimension, which peaked at $28 \%$ of respondents aged 60 to 69 and then decreased slightly.

Figure 1 shows the mean visual analogue scale values for each age group and the 95\% confidence interval. The mean value decreased from about 87 in the youngest age group to 72 in the oldest age group. Mean values did not differ significantly in the 20 to 49 age range but decreased significantly for respondents aged $\geqslant 50(\mathrm{P}<0.001)$.

\section{Health and sex}

Women aged $\geqslant 70$ tended to report higher rates of problems than did men of the same age (table 2). A systematic difference in rates was found across all age groups on the anxiety/depression dimension, with women reporting significantly higher rates than men $(\mathrm{P}<0.05)$. No significant differences were found in the visual analogue scale scores for men and women.

\section{Health and marital status}

Respondents who were widowed, separated, or divorced reported significantly more problems on all five dimensions $(\mathrm{P}<0.001)$. Scores on the visual analogue scale for this group were also significantly lower than for respondents living alone or for those
Table 1 Numbers (percentages) of respondents reporting a problem in each EuroQoL dimension

\begin{tabular}{lccc} 
& \multicolumn{3}{c}{ Problem } \\
\cline { 2 - 4 } EuroQoL dimension & Moderate & Extreme & Any \\
\hline Mobility & $620(18.3)$ & $3(0.1)$ & $623(18.4)$ \\
\hline Self care & $139(4.1)$ & $5(0.1)$ & $144(4.2)$ \\
\hline Usual activities & $481(14.2)$ & $70(2.1)$ & $551(16.3)$ \\
\hline Pain/discomfort & $988(29.2)$ & $129(3.8)$ & $1117(33.0)$ \\
\hline Anxiety/depression & $648(19.1)$ & $62(1.8)$ & $710(20.9)$ \\
\hline Any dimensions* & $1441(42.4)$ & $212(6.2)$ & $1456(43.1)$
\end{tabular}

${ }^{*}$ Although row totals within dimension are internally consistent, there is apparent anomaly in the final row. 1441 respondents reported a moderate problem in at least one dimension and 212 reported an extreme problem; these two dimensions are not mutually exclusive as respondents may have reported an extreme problem in one dimension, with no intermediate level of problem being reported for remaining dimension. Hence total of 1456 does not equate to addition of two previous table entries.

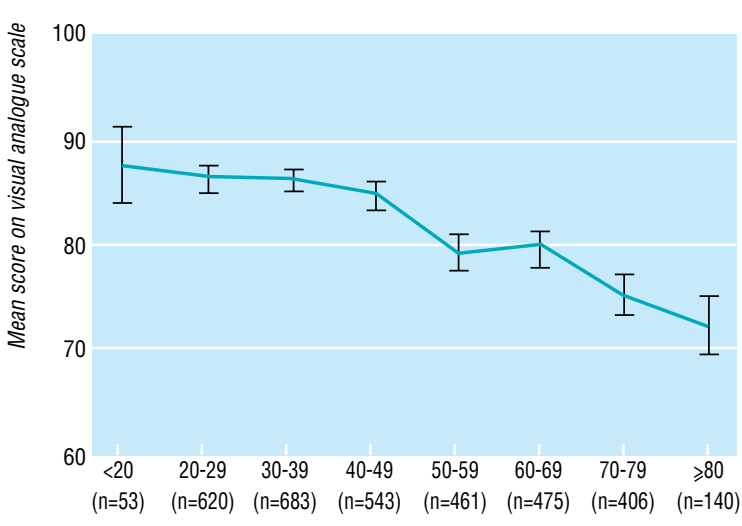

Age group (years)

Fig 1 Mean self rated health status of respondents

with a partner (means 77,84 , and 84 respectively, $\mathrm{P}<0.001)$.

\section{Health and social class}

After the effects of age were controlled for, there were significant differences in the rates of reported problems when respondents were grouped according to social class (table 3 ).

Table 2 Numbers (percentages) of respondents reporting any problem, by age group and sex

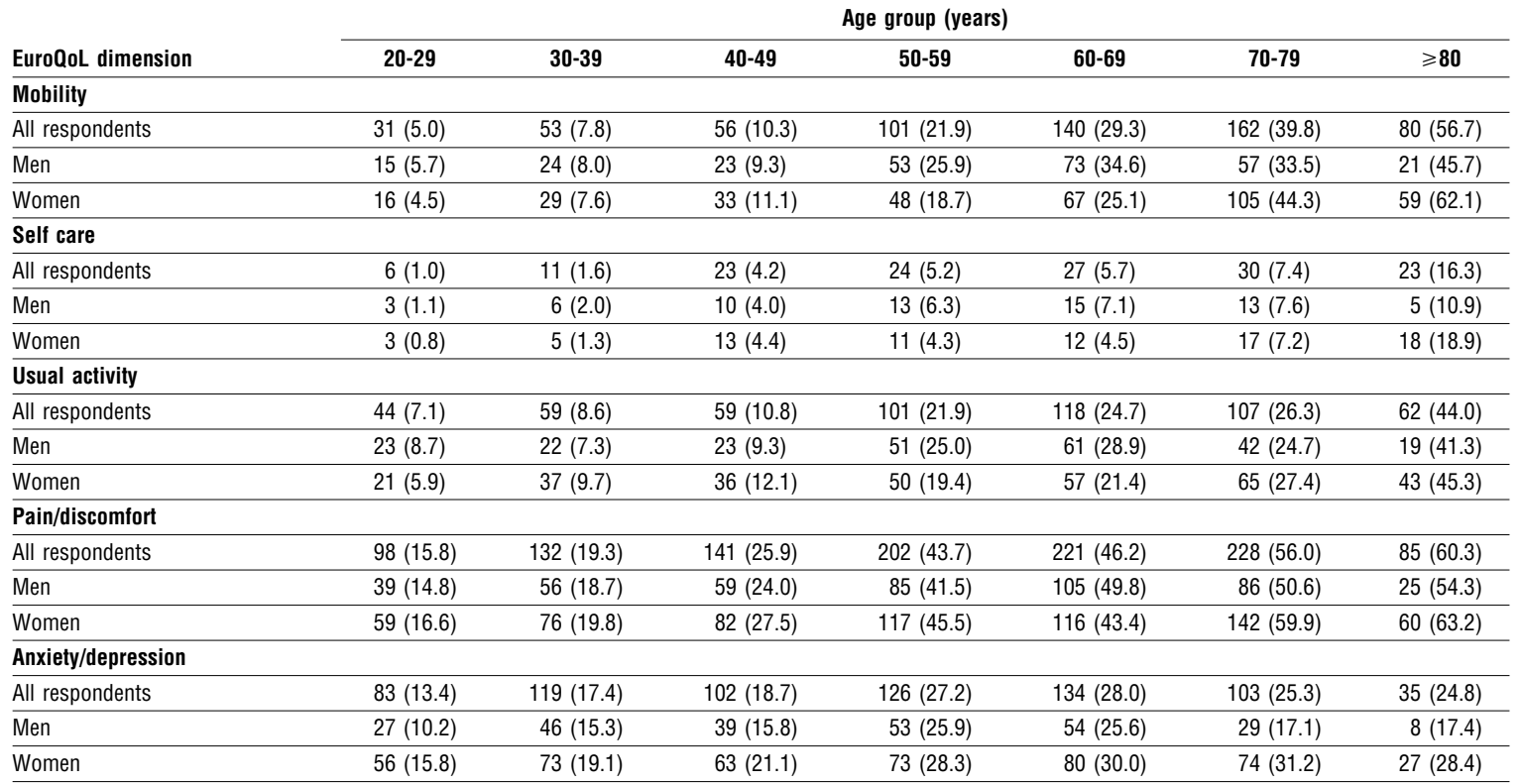


Table 3 Numbers (percentages) of respondents reporting any problem, by age group and social class (based on respondent's own current or most recent occupation as classified by registrar general)

\begin{tabular}{|c|c|c|c|c|c|c|c|}
\hline \multirow[b]{2}{*}{ EuroQoL dimension } & \multicolumn{7}{|c|}{ Age group (years) } \\
\hline & $20-29$ & $30-39$ & $40-49$ & $50-59$ & $60-69$ & $70-79$ & $\geqslant 80$ \\
\hline \multicolumn{8}{|l|}{ Mobility } \\
\hline \multicolumn{8}{|l|}{ Social class: } \\
\hline I and II & $6(3.6)$ & $18(7.6)$ & $15(7.6)$ & $17(14.3)$ & $42(28.4)$ & $24(29.6)$ & $11(47.8)$ \\
\hline III & $12(4.4)$ & $21(7.3)$ & $26(11.8)$ & $47(23.5)$ & $56(26.7)$ & $80(39.8)$ & $36(57.1)$ \\
\hline IV and V & $11(7.7)$ & $9(6.3)$ & $15(12.4)$ & $36(26.5)$ & $40(36.7)$ & $52(46.4)$ & $28(59.6)$ \\
\hline \multicolumn{8}{|l|}{ Self care } \\
\hline \multicolumn{8}{|l|}{ Social class: } \\
\hline I and II & $1(0.6)$ & $4(1.7)$ & $7(3.5)$ & $5(4.2)$ & $7(4.8)$ & $3(3.7)$ & $3(13.0)$ \\
\hline III & $2(0.7)$ & $4(1.4)$ & $10(4.5)$ & $10(5.0)$ & $12(5.7)$ & $17(8.5)$ & $7(11.8)$ \\
\hline IV and V & $2(1.4)$ & $2(1.4)$ & $6(5.0)$ & $9(6.7)$ & $7(6.4)$ & $10(8.9)$ & $11(23.4)$ \\
\hline \multicolumn{8}{|l|}{ Usual activities } \\
\hline \multicolumn{8}{|l|}{ Social class: } \\
\hline I and II & $11(6.5)$ & $16(6.8)$ & $19(9.6)$ & $17(14.3)$ & $37(25.0)$ & $19(23.5)$ & $8(34.8)$ \\
\hline III & $16(5.9)$ & $20(7.0)$ & $23(10.4)$ & $45(22.5)$ & $46(21.9)$ & $54(26.9)$ & $28(44.4)$ \\
\hline IV and V & $13(9.1)$ & $18(12.6)$ & $16(13.2)$ & $38(27.9)$ & $32(29.6)$ & $32(28.6)$ & $21(44.7)$ \\
\hline \multicolumn{8}{|l|}{ Pain/discomfort } \\
\hline \multicolumn{8}{|l|}{ Social class: } \\
\hline I and II & $24(14.3)$ & $39(16.5)$ & 38 (19.2) & $33(27.7)$ & $62(41.9)$ & $36(44.4)$ & $9(39.1)$ \\
\hline III & $42(15.6)$ & $45(15.7)$ & $69(31.4)$ & $98(49.0)$ & $93(44.3)$ & $111(55.2)$ & $43(68.3)$ \\
\hline IV and V & $26(18.2)$ & $41(28.7)$ & $33(27.3)$ & $69(50.7)$ & $62(56.9)$ & 77 (68.8) & $29(61.7)$ \\
\hline \multicolumn{8}{|l|}{ Anxiety/depression } \\
\hline \multicolumn{8}{|l|}{ Social class: } \\
\hline I and II & $15(8.9)$ & $37(15.6)$ & $31(15.7)$ & $25(21.0)$ & $28(18.9)$ & $14(17.3)$ & $6(26.1)$ \\
\hline III & $36(13.3)$ & $47(16.4)$ & $41(18.6)$ & $59(29.4)$ & $58(27.6)$ & $55(27.4)$ & $13(20.6)$ \\
\hline IV and V & $25(17.5)$ & $33(23.1)$ & $29(24.0)$ & $39(28.7)$ & $45(41.3)$ & $31(27.7)$ & $14(29.8)$ \\
\hline
\end{tabular}

Rates of reported problems from respondents in social classes III and IV were between 20\% and 120\% higher than rates in respondents from social classes I and II; the largest differences were for the pain/ discomfort $(\mathrm{P}<0.01)$ and anxiety/depression $(\mathrm{P}<0.01)$ dimensions. Rates did not differ significantly for the mobility and self care dimensions. Figure 2 shows that respondents from social classes I and II had consistently higher levels of reported health as measured by the visual analogue scale than respondents from the two other social classes. Respondents from social classes I and II had a 5 point advantage on the visual analogue scale over respondents from social classes IV and V of the same age group. The difference was significant for all age groups except for respondents aged 40 to 49 years. The mean scores on the visual analogue scale for respondents from social classes I and II remained above the level of the youngest respondents from social classes IV and V until the 50 to 59 age group.

\section{Health and education}

When respondents were classified by education rather than by social class, a similar pattern of differences emerged. Respondents who had received higher or further education reported significantly lower rates of problems with mobility $(\mathrm{P}<0.05)$, usual activities $(\mathrm{P}<0.05)$, pain/discomfort $(\mathrm{P}<0.01)$, and anxiety/ depression $(\mathrm{P}<0.01)$ than did those who had received no education after leaving school. A similar pattern was seen on the visual analogue scale, with significantly higher scores reported for those who had received higher or further education $(\mathrm{P}<0.001)$.

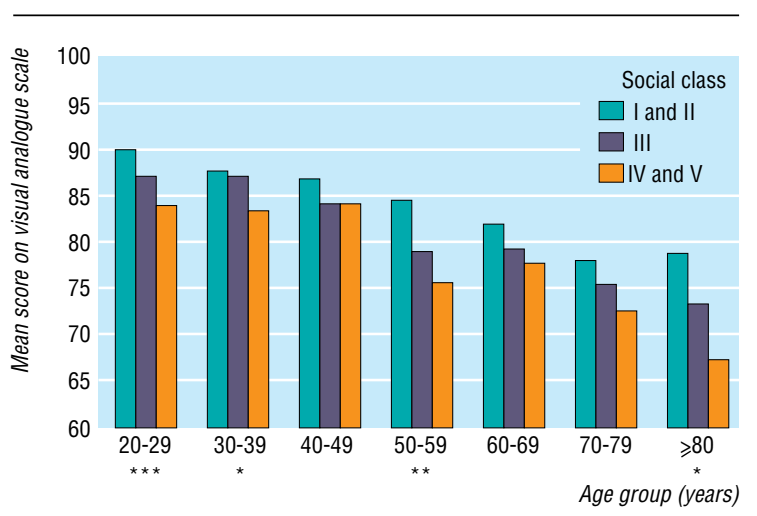

Fig 2 Effect of social class on self rated health status. ${ }^{*} \mathrm{P}<0.05$; ${ }^{\star *} \mathrm{P}<0.01 ;{ }^{* *} \mathrm{P}<0.001$

\section{Health and economic status}

Significantly higher rates of problems were reported by respondents who were unemployed, sick or disabled, or retired, compared with those in employment or full time education $(\mathrm{P}<0.001)$ (table 4$)$. Rates of reported problems for unemployed people were almost twice those of respondents in a salaried job.

When respondents were grouped according to housing tenure, significantly higher rates of problems were recorded on all the dimensions for those living in rented property compared with owner occupiers.

The mean scores on the visual analogue scale of people in work or of people who were studying was significantly higher than for people who were unemployed (87.5 and 82.0 respectively, $\mathrm{P}<0.001)$. Similarly, the scores of owner occupiers were significantly higher than for people who rented their accommodation (85.1 and 77.2 respectively, $\mathrm{P}<0.001$ ). 
Table 4 Numbers (percentages) of respondents reporting problems, by employment

EuroQoL dimension

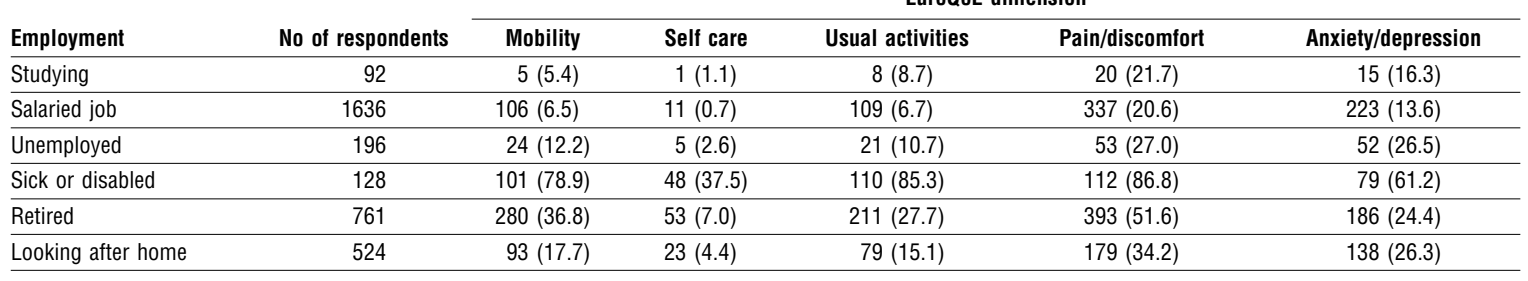

${ }^{*}$ The table excludes 45 respondents whose employment was classed as other and 12 respondents whose details were missing.

\section{Health and smoking behaviour}

Respondents who smoked reported significantly higher rates of problems than non-smokers on all dimensions. Non-smokers also recorded significantly higher scores on the visual analogue scale than respondents who smoked $(83.4$ and 80.4 respectively, $\mathrm{P}<0.001)$.

\section{Analysis of variance}

Analysis of variance was used to investigate the collective influence of background variables. With the score on the visual analogue scale as the dependent variable and age as a covariate, a main effects model indicated a significant contribution for education $(\mathrm{P}<0.01)$, employment $(\mathrm{P}<0.001)$, and smoking behaviour $(\mathrm{P}<0.001)$. Housing tenure, marital status, and social class were not significant variables in this model.

\section{Disability rates from other national surveys}

Respondents who reported any problem in any dimension could be distinguished from respondents who reported no problems whatsoever. This dichotomy can be used to form an arbitrary definition of disability, enabling data to be compared with the findings of other surveys. The general household survey incorporates questions on longstanding illness and recent interference with usual activities. ${ }^{19}$ The responses to these questions are combined to give rates of limiting longstanding illness which are published annually. The disability survey by the Office of Population Censuses and Surveys conducted in 1985 included a questionnaire comprising 10 categories: locomotion, reaching and stretching, dexterity, seeing, hearing, personal care, continence, communication, behaviour, and intellectual functioning. ${ }^{20}$ The rates of disability in people grouped into five year age groups were reported in this survey. ${ }^{20}$ These data were plotted against disability rates determined from our survey (fig 3). Disability rates based on responses to the EQ-5D questionnaire were $20 \%$ to $25 \%$ higher than rates from the general household survey for all age groups and about 30\% to 40\% higher than the 1985 disability survey, until the age of 80 .

\section{Discussion}

This survey provides an important insight into the health status of the population of the United Kingdom at any one time. Although extreme problems with mobility and self care were rarely reported in this survey, there was a high level of reported problems with pain or discomfort. Over $50 \%$ of respondents aged $\geqslant 70$ and about $20 \%$ of the youngest respondents reported some problem in this dimension. This finding

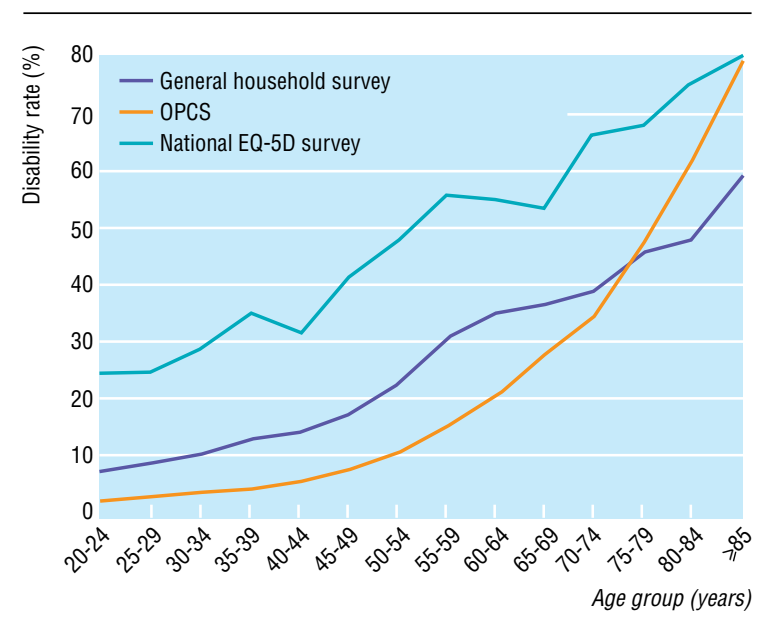

Fig 3 Disability rates from three national surveys

has important implications. Pain does not seem to be a dimension of interest in a national disability survey despite being widely experienced in the community. The omission of a pain category means that it is assigned a zero weight, despite good evidence that it has a powerful influence on society's valuations of states of health. ${ }^{21}$ These factors combine to disadvantage a significant proportion of the general population.

Significant differences were found between population subgroups with respect to age, social class, marital status, employment, education, and smoking behaviour. These findings compare with findings reported elsewhere. ${ }^{22-24}$ Disability rates based on the EuroQoL classification reflected similar trends to those seen in the general household survey and surveys of the Office of Population Censuses and Surveys, although rates in these surveys were somewhat lower as they were based on a narrower definition of disability.

\section{Population averages}

The representativeness of the survey suggests that the results are indicative of the average health status in the general population of the United Kingdom, although it should be borne in mind that sampling was limited to individuals living in the community and tended to exclude people who had extreme problems with mobility or with self care and therefore likely to be dependent on others for their daily needs. Current investigation of specific patient groups-for example, people attending their general practice surgeriesreveals a wider distribution of reported problems. Thus, to the extent that this survey excluded people who were likely to yield responses indicating more severe problems, the results may well underestimate the health related quality of life of the general population. 
Key messages

- Measurement of health outcome requires the observation of states of health

- Patients' involvement in recording and assessing their own state of health is a major element in the process of evaluating the impact of health care

- The EuroQoL EQ-5D questionnaire highlights variations in states of health which are consistent with previously published results

- High degrees of pain are reported in the general population. A category for pain is absent and thus undetected in the survey of disability by the Office of Population Censuses and Surveys

Our data can be treated as descriptive population "norms." As such, they could provide baseline values for monitoring variations in health for specific population groups, particularly if this information was also linked to local epidemiological data. In aggregate form, such information could be used to complement national targets by providing a measure based on health status rather than mortality. The capacity of the EQ-5D questionnaire to generate quantifiable and usable information on the health status of a population led to its inclusion in the 1996 health survey for England. ${ }^{25}$

\section{Measuring outcomes}

However, it is the measurement of change in health status for which the need is greatest. There can be few circumstances in which healthcare workers are not concerned with the measurement of outcome, and the EQ-5D questionnaire provides the capacity to measure change in health status, and hence outcomes, in a simple standardised way. The information on self reported problems recorded on the first page of the EQ-5D questionnaire identifies a unique health status for which there is a corresponding index value based on the views of the general population. ${ }^{21}$ Changes in health status and the value of that change can be used to quantify outcomes for clinical and economic evaluation; the latter role was recommended for the EQ-5D questionnaire in a report commissioned by the United States Department of Public Health. ${ }^{26}$ There is "an increasing consensus regarding the centrality of the patient's point of view in monitoring medical care outcomes, ${ }^{, 6}$ and the EQ-5D questionnaire has the obvious potential to contribute to that process. The national survey data reported in this paper show what can be achieved by using an uncomplicated instrument for measuring health status. The further exploitation of its potential is open to us all.

Survey work for the 1993 survey was conducted by Social and Community Planning Research, and we thank the trained fieldwork staff for their help in the collection of the data.

Contributors: All four authors shared equally in the design and execution of the research reported in this paper. Social and Community Planning Research provided significant additional expertise in the design and management of the national survey. PK will act as guarantor for the paper.

Funding: The project was funded by the Department of Health. The views expressed are those of the authors and not necessarily of the Department of Health.

Conflict of interest: None.

Patrick DL, Bush JW, Chen MM. Methods for measuring levels of well-being for a health status index. Health Serv Res 1973;11:516.

2 Rosser RM, Watts V. The measurement of hospital output. Int J Epidemiol $1972 ; 1: 361-8$.

\section{Appendix}

\begin{tabular}{|c|c|c|}
\hline Your own health state today & Your own health state today & \\
\hline $\begin{array}{l}\text { By placing a tick in one box in each group below, please indicate which } \\
\text { statement best describes your own health state today. } \\
\text { Do not tick more than one box in each group. } \\
\text { Mobility } \\
\text { I have no problems in walking about } \\
\text { I have some problems in walking about } \\
\text { I am confined to bed } \\
\text { Self-care } \\
\text { I have no problems with self-care } \\
\text { I have some problems washing and dressing myself } \\
\text { I am unable to wash and dress myself } \\
\text { Usual activities (eg. work, study, housework, family or leisure activities) } \\
\text { I have no problems with performing my usual activities } \\
\text { I have some problems with performing my usual activities } \\
\text { I am unable to perform my usual activities } \\
\text { Pain/discomfort } \\
\text { I have no pain or discomfort } \\
\text { I have moderate pain or discomfort } \\
\text { I have extreme pain or discomfort } \\
\text { Anxiety/depression } \\
\text { I am not anxious or depressed } \\
\text { I am moderately anxious or depressed } \\
\text { I am extremely anxious or depressed }\end{array}$ & $\begin{array}{l}\text { To help people say how good } \\
\text { or bad a health state is, we have } \\
\text { drawn a scale (rather like a } \\
\text { thermometer) on which the best } \\
\text { state you can imagine is marked } \\
100 \text { and the worst state you can } \\
\text { imagine is marked } 0 \text {. } \\
\text { We would like you to indicate on this } \\
\text { scale how good or bad your own } \\
\text { health is today, in your opinion. } \\
\text { Please do this by drawing a line from } \\
\text { the box below to whichever point on } \\
\text { the scale indicates how good or bad } \\
\text { your health state is. } \\
\text { Your own } \\
\text { health state } \\
\text { today }\end{array}$ & 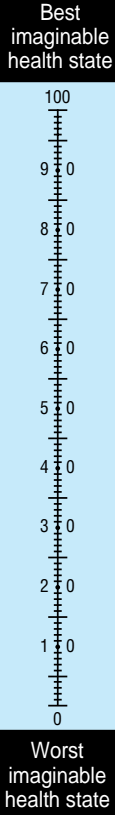 \\
\hline
\end{tabular}

$E Q-5 D$ questionnaire 
Bergner M, Bobbitt RA, Kressel S, Pollard WE, Gilson BS, Morris JR. The sickness impact profile: conceptual formulation and methodology for the development of a health status measure. Int J Health Serv 1976;6:393-415.

4 Hunt SM, McKenna SP, McEwen J, Backett EM, Williams J, Papp E. A quantitative approach to perceived health status: a validation study. J Epidemiol Community Health 1980;34:281-6.

5 Torrance GW, Furlong W, Feeny D, Boyle M. Multi-attribute preference functions. Pharmacoeconomics 1995;7:503-20.

6 Ware JE, Sherbourne CD. The MOS 36-item short-form health survey (SF-36). I. Conceptual framework and item selection. Med Care 1992;30:473-83.

7 Sintonen $\mathrm{H}$. An approach to measuring and valuing health states. Soc Sci Med 1981;15:55-65.

EuroQoL Group. EuroQoL-a new facility for the measurement of health-related quality of life. Health Policy 1990;16:199-208.

9 Brooks RG. EuroQoL-the current state of play. Health Policy 1996;37:5372.

10 Williams AH. The measurement and valuation of health: a chromicle. University of York: Centre for Health Economics, 1995. (Discussion paper 136.)

11 Brazier J, Jones N, Kind P. Testing the validity of the EuroQoL and comparing it with the SF-36 health survey questionnaire. Qual Life Res 1993;2:169-80

12 Van Agt H, Essink-Bot M-L, Krabbe P, Bonsel G. Test-retest reliability of health state valuations collected with the EuroQoL questionnaire. Soc Sci Med 1994:39:1537-44

13 Essink-Bot M-L, Krabbe P, Bonsel G, Aaronson N. An empirical comparison of four generic health status measures: the Nottingham health profile, the medical outcomes study 36 -item short-form health survey, the COOP/WONCA charts, and the EuroQoL Instrument. Med Care 1997;35:522-37.

14 Hurst NP, Jobanputra P, Hunter M, Lambert M, Lochead A, Brown H. Validity of EuroOoL - a generic health status instrument-in patients with rheumatoid arthritis. Br J Rheumatol 1994;33:655-62.
15 Sculpher M, Dwyer N, Byford S, Stirrat G. Randomised trial comparing hysterectomy and transcervical endometrial resection: effect on health related quality of life and costs two years after surgery. Br J Obstet Gynaecol related quality of lif

16 Hollingworth W, Mackenzie R, Todd CJ, Dixon AK. Measuring changes in quality of life following magnetic resonance imaging of the knee: SF-36, EuroQoL or Rosser index? Qual Life Res 1995;4:325-34.

17 Erens B. Health-related quality of life: general population survey. London: Social and Community Planning Research, 1994. (Technical report.)

18 Kish L. Survey sampling. New York: Wiley, 1965.

19 Thomas M, Goddard E, Hickman M, Hunter P. The general household survey 1992. London: HMSO, 1994. (OPCS Series GHS No 23.)

20 Martin J, Letzer H, Elliot D. The prevalence of disability among adults. OPCS surveys of disability in Great Britain. Report 1. London: HMSO, 1988.

21 Dolan P, Gudex C, Kind P, Williams A. A social tariff for EuroOoL: results from a UK general population survey. University of York: Centre for Health Economics, 1995. (Discussion paper 138.)

22 Department of Health and Social Security. Prevention and health: everybody's business. A reassessment of public and personal health. London: HMSO, 1976

23 Black D, Morris JN, Smith C, Townsend P. Black Report. Inequalities in health: report of a research working group. London: Department of Health and Social Security, 1980.

24 Rahkonen O, Arber S, Lahelma E. Health inequalities in early adulthood: a comparison of young men and women in Britain and Finland. Soc Sci Med 1995;41:163-71.

25 Prescott-Clarke P, Primatesta P, eds. Health survey for England, 1996. London: Stationery Office, 1998

26 Weinstein MC, Siegel JE, Gold MR, Kamlet MS, Russell LB. Recommendations of the panel on cost-effectiveness in health and medicine. JAMA 1996;276:1253-8.

(Accepted 31 October 1997)

\title{
Use of calcium channel blockers and risk of suicide: ecological findings confirmed in population based cohort study
}

\author{
Gunnar Lindberg, Kerstin Bingefors, Jonas Ranstam, Lennart Råstam, Arne Melander
}

\begin{abstract}
Objective: To investigate possible associations between use of cardiovascular drugs and suicide. Design: Cross sectional ecological study based on rates of use of eight cardiovascular drug groups by outpatients. A population based cohort study including users of drugs to control hypertension. Subjects: The ecological study included 152 of Sweden's 284 municipalities. The cohort study included all inhabitants of one Swedish municipality who during 1988 or 1989 had purchased cardiovascular agents from pharmacies within the municipality. Six hundred and seventeen subjects $(18.2 \%)$ were classified as users of calcium channel blockers and $2780(81.8 \%)$ as non-users.

Main outcome measures: Partial correlations (least squares method) between rates of use of cardiovascular drugs and age standardised mortality from suicide in Swedish municipalities. Hazard ratios for risk of suicide with adjustments for difference in age and sex in users of calcium channel blockers compared with users of other hypertensive drugs. Results: Among the Swedish municipalities the use of each cardiovascular drug group except angiotensin converting enzyme inhibitors correlated significantly and positively with suicide rates. After adjustment for the use of other cardiovascular drug groups, as a substitute for the prevalence of cardiovascular morbidity, only the correlation with calcium channel
\end{abstract}

blockers remained significant $(r=0.29, \mathrm{P}<0.001)$. In the cohort study, five users and four non-users of calcium channel blockers committed suicide during the follow up until the end of 1994. The absolute risk associated with use of calcium channel blockers was 1.1 suicides per 1000 person years. The relative risk, adjusted for differences in age and sex, among users versus non-users was 5.4 (95\% confidence interval 1.4 to 20.5).

Conclusions: Use of calcium channel blockers may increase the risk of suicide.

\section{Introduction}

A recent epidemiological study reported an excess risk of depression requiring pharmacological treatment after treatment with calcium channel blockers and angiotensin converting enzyme inhibitors but not after treatment with digoxin, anti-arrhythmics, nitrates, diuretics, or $\beta$ blockers. ${ }^{1}$ There have also been case reports suggesting depression ${ }^{2-5}$ as well as psychosis ${ }^{6}$ after treatment with calcium channel blockers. As depression may promote suicide we investigated possible ecological associations between suicide rates and the rates of use of eight cardiovascular drug groups in 152 Swedish municipalities. In addition, we investigated the risk of suicide in users and non-users of calcium channel blockers who had purchased prescription drugs mainly used to treat hypertension.
Swedish Network for Pharmacoepidemiology, Foundation, Malmö University Hospital, SE-205 02 Malmö, Sweden

Gunnar Lindberg, clinical epidemiologist Jonas Ranstam, biostatistician

Arne Melander, professor

Department of Pharmaceutical Services Research, Uppsala University, Box 586, SE-751 23 Uppsala, Sweden

Kerstin Bingefors, senior lecturer

Department of Community Medicine, Lund University, Malmö University Hospital, SE-205 02 Malmö Lennart Råstam, professor

Correspondence to: Dr Lindberg gunnar.lindberg@ nepia.se

BMJ 1998;316:741-5 